\title{
Monitoring of Ionizing Radiation and Rain Intensity during May to October 2015 in São José dos Campos, Brazil
}

\author{
Inácio Malmonge Martin, Thiago Adriano dos Santos, Franklin Andrade da Silva, Marcelo Pego Gomes and \\ Bogos Nubar Sismanoglu \\ Physics Department, Institute Technological of Aeronautics (ITA), São José dos Campos 12228-900, Brazil
}

\begin{abstract}
Radiation affects the environment and local human activity in any location of the earth's surface. Due to this fact, the aim of this study was to monitor the ionizing radiation and rain intensity using portable devices. During May 23 to October 2, 2015, it was made measures the intensity of gamma radiation from $30 \mathrm{keV}$ to $10.0 \mathrm{MeV}$ at a height of 25 meters in São José dos Campos city, SP, Brazil. It was used a crystal of sodium iodide scintillator $3 \times 3$ inches coupled to a photomultiplier and associated electronic. The measurements were made continually with minute's interval throughout the period and it was monitored rain intensity every minute at the same height of the tower. In this job, it was possible to correlate rain-radiation and it was observed which gamma radiation has a directly proportional relationship with rain and visible frequency of 1 day.
\end{abstract}

Key words: Gamma radiation, rain intensity, radon gas, gamma scintillator.

\section{Introduction}

Ionizing radiation present near the earth's surface in any location depends on the latitude, the rainy or dry season, and the local geology [1-4]. The primary and secondary cosmic radiation also contributes to the presence of ionizing radiation near the earth's surface. Monitoring of meteorological and environmental parameters is an inalienable part of agencies responsible for public health activities, weather forecasting and civil protection and there is no need to justify the importance of developing more effective methods for affecting this task [5,6]. Environmental radioactivity is generally regarded as an adverse factor causing heavy damage to human health and the environment, therefore, ionizing radiation has been monitored on a global scale a few decades ago [7, 8]. Thus, results of the radiation level are accumulated in large amounts for the purpose to verify its variation in different situations as geographic location, climatic

Corresponding author: Inácio Malmonge Martin, Ph.D., research fields: magnetic field, radiation and solar plasma. conditions and industrial activities. At this stage, the connection between natural radioactivity and weather was revealed and statistically proven $[9,10]$. In many cases, results of environmental radiation measurements cannot be interpreted correctly to be analyzed without consideration of meteorological parameters. For example, increase of radiation during storms can cause up to a false alarm nuclear plant radiation leak [11, 12]. On the other hand, it is naturally expected that the links between meteorological parameters and environmental radiation variations can be used to obtain more information about its effects and meteorological parameters. The objective of this work is to develop methods for meteorological and environmental observations based on measurements of natural radioactivity in the local site.

\section{Experimental Setup}

To monitor the $\mathrm{X}$ and gamma radiation range between $30 \mathrm{keV}$ and $10.0 \mathrm{MeV}$, it has been used a portable system composed of a scintillator sodium iodide activated with Thallium $\mathrm{NaI}(\mathrm{Tl})$. This crystal 3 
$\times 3$ inches wrapped in a thin cylinder of aluminum coupled with a photomultiplier with source power circuit in 1,400 VDC and with data acquisition system provided by the company (Aware Electronics-Inc., USA). The rainfall intensity in $\mathrm{mm}$ at each sampling minute was observed through a system (bascule/bucket) rain gauge and datalogger acquisition developed in ITA according to the recommendations provided by document [13].

Both systems (radiation + rain gauge) are portable and easy to operate. The tests carried out before the measures described in this paper show the perfect operation of the equipment [13].

\section{Experimental Results}

It may showed in Fig. 1 that from 23 May 2015 until 110,000 minutes of monitoring rainfall on place only small rainfall intensity appears around about 47,000 minutes after the start. It is observed as a result one increase in radiation intensity, going from the background of 34,500 counts/min to the value of 36,500 counts $/ \mathrm{min}$. In the meantime, 110,000 minutes, the level of measured gamma radiation has a visible frequency of 1 day. This change (day/night) is determined by the greater or lesser presence of radon gas (Rn-222 and Rn-220). The decay of radon progenies produce $\mathrm{X}$-rays and gamma in the range measured by the detector. Already during the exact period of rainfall intensity, the gamma radiation increases due to air washing bringing radon gas closer to earth's surface. This fact is clearly visible in Fig. 1 in instants near 47,000 minutes, 110,000 minutes and 140,000 minutes after the start of the measurements. When rain continues for a long time (steady rain), only the first few minutes of precipitation is perceived increased radiation. Examining in detail, Fig. 1 shows a visible good correlation between the presence of rain and increasing the $\mathrm{X}$ and gamma radiation in the region.

\section{Conclusions}

It was observed in measurements of $\mathrm{X}$ and gamma radiation two important facts. During dry periods, the variation in the intensity of this radiation is periodic. This 24 hour period is well visible in the time interval measured between 50,000 minutes to 100,000 minutes
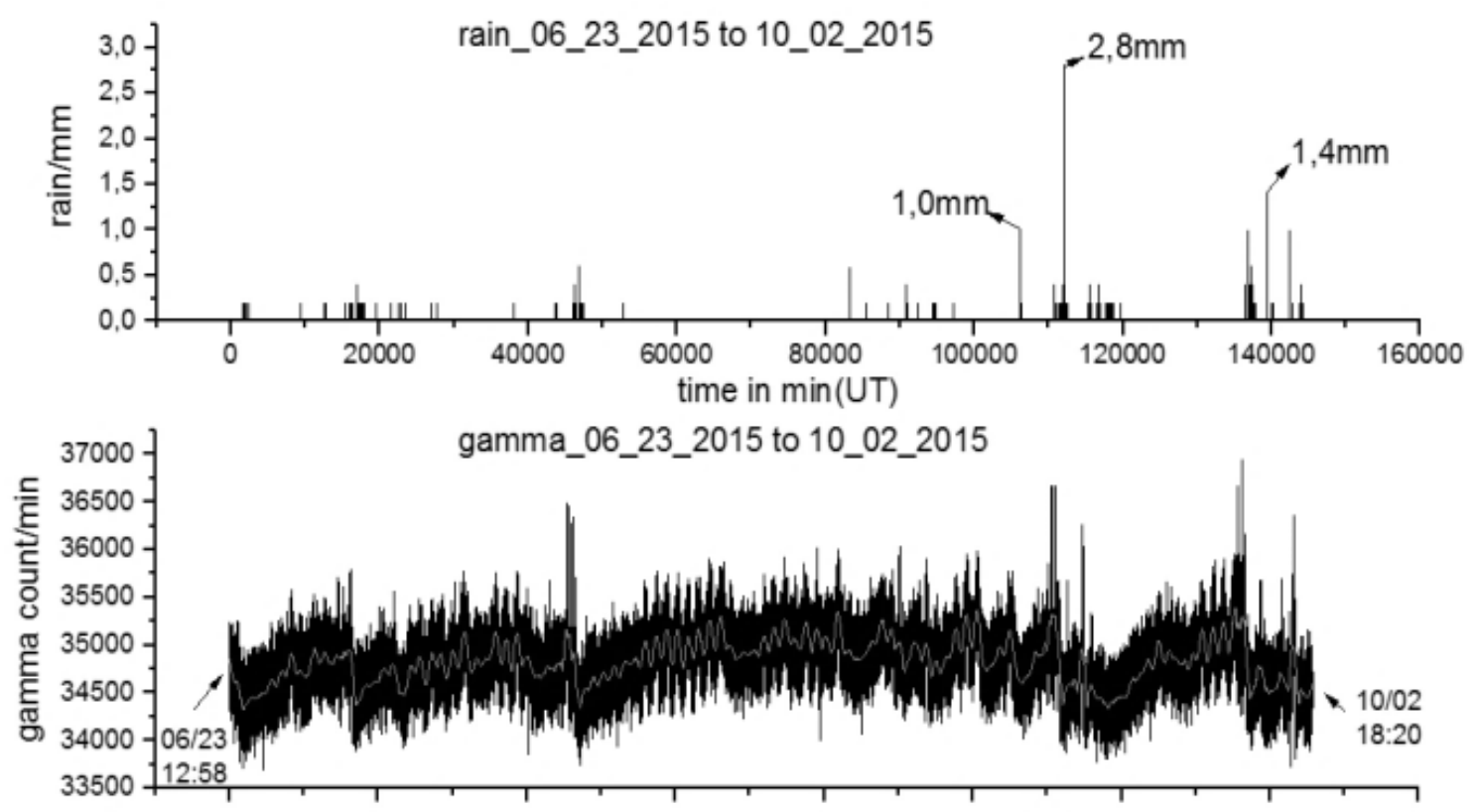

time in $\min ($ UT)

Fig. $1 \mathrm{X}$ and gamma rays counts per minute and rain intensity in $(\mathrm{mm}) / \mathrm{min}$ in same local time. 
from the beginning. Exactly in the same period checking, it is found that very little rain intensity appeared. Thus, the radiation is in this period originated mainly for the radon gas progenies exhaled from the earth's crust. In the range from $110,000-120,000$ minutes and 135,000-150,000 minutes, existing local rains that caused increased $\mathrm{X}$ and gamma radiation. It was conclude which in the tropics becomes possible to measure rainfall by measurements of radiation $\mathrm{X}$ and gamma in same local range near the ground level. It is necessary to work on perfect calibration rain/radiation intensity parameters for using this method.

\section{Acknowledgments}

The author thanks Institute Technological of Aeronautics (ITA), CAPES and CNPq research agencies for extending financial and fellowship support to implement the project.

\section{Reference}

[1] Bhandri Rama, N. 1963. "Study of Atmospheric Washout Processes by Means of Radon Decay Products." Journal of Geophysical Research 68 (13): 3823-3826.

[2] Brunetti, M., Cecchini, S., Galli, M., Giovannini, G., Longo, G., and Pagliarin, A. 1999. "Environmental Radiation Monitoring at High Latitude." In Proceedings of 26th ICRC, 3552.

[3] Brunetti, M., Cecchini, M. S., Galli, M., Giovannini, G., and Pagliarin, A. 2000. "Gamma-Ray Bursts of Atmospheric Origin in the MeV Energy Range." Geophysical Research Letters 27 (11): 1599-1602.

[4] Greenfield, M., Domondon, A., Tsuchiya, S., Kubo, K., Ikeda, Y., and Tomiyama, M. 2003. "Near-Ground Detection of Atmospheric $\gamma$ Rays Associated with Lightning.” Journal of Applied Physics 93 (3): 1839-1844.

[5] Gusev, A. A., Martin, I. M., Alves, M. A., and Junior, A. A. 2015. "Simulation of the Radiation Fallout from Gamma-Ray Measurements." Modeling Earth Systems and Environment 1: 18.

[6] Gomes, M. G., and Martin, I. M. 2013. "Simultaneous Measurements of Rainfall Intensity, Low Energy Neutrons and Gamma Radiation in São Jose dos Campos, SP, Brazil." Journal of Environmental Science and Engineering 9: 161-167.

[7] Jayanthi, U. B., Gusev, A. A., Neri, J. A. C. F. T., Villela, O. P. J., Pugacheva, G. I., and Talavera, K. C. et al. 2005. "Ground Gamma Radiation Associated with Lightning and Rain Precipitation.” In 29th International Cosmic Ray Conference, 177-180.

[8] Martin, I. M., Gusev, A. A., Santos, T. A., and Sismanoglu, B. N. 2015. "Radon Gas and Increasing Intensity of Gamma Radiation near Ground Level Interface on 2011 in Sao Jose dos Campos, SP, Brazi." International Journal of Research in Engineering \& Technology 3: 31-38.

[9] Martin, I. M., Gomes, M. P., Sismanoglu, B. N., and Santos, T. A. 2016. "Measurements of Decay Products from Rn-222 and Rn-220 near Ground Level and Low Atmosphere in São José dos Campos, SP, Brazil." International Journal of Research in Engineering \& Technology 4 (3): 1-6.

[10] Martin, I. M., Gomes, M. P., Sismanoglu, B. N., and Lindo, N. C. 2015. "Daily Variability of Radon Gas in Brazilian Tropics near Ground Level Surface." Journal of Environmental Science and Engineering A 4: 516-521.

[11] Martin, I. M., Germano, J. S. E., and Takaki, T. M. 2013. "ITA-DATALOGGER: Continuous Monitoring of Pressure, Relative Humidity, Temperature, Rainfall Intensity and Dose of Ionizing Radiation near the Surface of the Earth in São José dos Campos, SP, Brazil.” In $65 a$ Annual Meeting of Brazilian Science for Progress Society (SBPC), 57-62.

[12] Martin, I. M., and Gomes, M. P. 2013. "Intensity Variation of Gamma Radiation on Ground Level Interface in São José dos Campos, SP, Brazil." Environmental Science 8: 79-82.

[13] Tsukuda, T. 2008. "Radon-Gas Monitoring by Gamma-Ray Measurements on the Ground for Detecting Crustal Activity Changes, Preliminary Study by Repeat Survey Method." Bulletin of the Earthquake Research Institute 83: 227-241. 